\title{
Gestão do conhecimento
}

como modelo de gestão de pessoas para uma microempresa do Setor Moveleiro de São Luís

Washington Silva do Espírito Santo, Yonara Costa Magalhães, Will Ribamar Mendes Almeida. 


\section{Gestão do conhecimento como modelo de gestão de pessoas para uma microempresa do Setor Moveleiro de São Luís}

\section{Knowledge management and people management model for a micro-enterprise of the furniture sector in São Luís.}

Washington Silva do Espírito Santo ${ }^{1}$, Yonara Costa Magalhães ${ }^{2}$, Will Ribamar Mendes Almeida ${ }^{3}$.

Resumo: Este trabalho mostra a gestão do conhecimento como conjunto de ações para uma microempresa do setor moveleiro na cidade de São Luís. Apresenta um modelo de gestão de pessoas utilizando práticas da gestão do conhecimento. Desta forma, a pesquisa foi de caráter analítico e explicativo, na qual o objeto de estudo foi explicar fatores que contribuem para o seu comportamento. Quanto às fontes utilizadas na coleta de dados, foi realizada uma pesquisa de campo, tendo em vista que os dados para a composição deste trabalho foram feitos in loco (observação direta), conjugada à pesquisa bibliográfica para a composição da fundamentação teórica. Como resultado de modelo de gestão de pessoas para microempresas do setor moveleiro de São Luís, serão apresentadas práticas de geração de conhecimento criado pela interação entre os participantes do processo produtivo moveleiro, assim como suas características, agentes envolvidos, tipos de conhecimento encontrados no processo de negócio e um modelo de gestão de pessoas, utilizando práticas da gestão do conhecimento que são vitais para o crescimento da microempresa. A relevância para realização desta pesquisa deve-se ao fato desse tema ser de pouco conhecimento por parte dos microempresários e, como isso, pode ser um fator que traga um diferencial no mercado, podendo ser o início de uma longa jornada para estudantes e universidades interessados em explorar o tema, a fim de expor a grupos de interesse e, com isso, estimular o crescimento de pequenos negócios em nossa cidade.

Palavras-chave: Gestão do Conhecimento. Gestão de Pessoas. Microempresas.

Abstract This work shows knowledge management as a set of 1 Bacharel em Sistemas de Informação. E-mail:wazhizgtoz@gmail.com Universidade Ceuma.

2 Professora Mestra em Engenharia de Eletricidade. Professora na Universidade CEUMA. E-mail: yonara.magalhaes@ceuma.br-Universidade Ceuma.

3 Doutor em Engenharia de Eletricidade. Professor na Universidade CEUMA. E-mail: will75@gmail.com- Universidade Ceuma. 
actions for a small company in the furniture sector in São Luis. Presents a people management model used practices of knowledge management. Thus, the research was analytical and explanatory character, in which the object of study was to explain factors contributing to their behavior. The sources used in data collection, field research was carried out, considering that the data for the composition of this work were made on-site (direct observation), conjugated to literature for the composition of the theoretical foundation. Because of people management model for the furniture sector microenterprises of São Luis, will be presented practices of knowledge generation, produced by the interaction between the participants of the furniture production process, as well as its characteristics, stakeholders, types of knowledge found in process business, which are vital for the growth of micro-enterprise. The relevance for this research due to the fact that little knowledge on the part of micro entrepreneurs and how it can be the beginning of a long journey for students and universities interested in exploring the topic in order to expose the interest groups and that stimulate the growth of small businesses in our town.

Key words: Knowledge management. People Management. Microenterprise.

\section{INTRODUÇÃO}

A Gestão do Conhecimento pode tornar os processos mais eficientes, operando uma evolução na eficácia da microempresa a partir do ponto de vista mercadológico. No mundo em constante processo de mudança, o assunto gestão do conhecimento é uma abordagem imprescindível para eficiência da gestão de pessoas e processos.

A Gestão do Conhecimento é importante para capacitar microempresa tornando-a mais competitiva, conduzindo as pessoas para contribuir com o crescimento do negócio e auxiliando na identificação de conhecimentos, habilidades e atitudes que as pessoas precisam desenvolver para atender aos objetivos estratégicos da empresa.

Deste modo, o cerne da gestão do conhecimento é a obtenção do conhecimento e pode ser combinada à estratégia da empresa, ajudando a atender às exigências táticas. $O$ tema a ser desenvolvido versará sobre a proposta de um modelo simples para realizar a Gestão do Conhecimento para uma microempresa do setor moveleiro na cidade de São Luís. Este artigo está subdividido nos seguintes itens: o referencial teórico, que aborda a Gestão do Conhecimento e suas definições, modos de conversão do conhecimento, Gestão de Pessoas, uma breve apresentação das características de microempresa no Brasil, o modelo proposto, seus resultados e conclusão da pesquisa. 


\section{CONCEITOS E FUNDAMENTOS SOBRE A GESTÃO DO}

CONHECIMENTO

\subsection{Conhecimento e Gestão do Conhecimento}

Para Uriarte (2008), a compreensão da gestão do conhecimento começa pelo entendimento conceitual do próprio conhecimento e sua distinção de informação e dados. Ainda, segundo Uriarte (2008), o que é essencial na criação de dados ou na criação de informação é o contexto. A existência de padrão de relação entre os dados gera conhecimento. A informação é dependente do contexto, já o conhecimento tende a criar o seu próprio contexto.

Nonaka (2008) e Uriarte (2008) estão de acordo ao apresentar o conhecimento como uma vantagem competitiva da organização. Para estes autores, sua realização dá-se pela utilização das informações e dados juntamente com o aproveitamento e a qualificação das pessoas e de suas ideias e é reconhecida como a nova estratégia das organizações:

Em uma economia onde a única certeza é a incerteza, a fonte certa de vantagem competitiva duradoura é o conhecimento. Quando os mercados transformam-se, as tecnologias proliferam, os competidores multiplicamse e os produtos tornam-se obsoletos quase do dia para noite, as empresas bem sucedidas são as que criam consistentemente novos conhecimentos, disseminamno amplamente pela organização e o incorporam rapidamente em novas tecnologias e produtos (NONAKA, 2008, p.23).

Uriarte (2008) ressalta que o conhecimento é o produto da organização, onde o raciocínio sistemático aplicado a dados e informações gera resultado e aprendizagem que fornece vantagem competitiva e sustentável e onde o conhecimento se torna um ativo essencial. Este autor apresenta dois tipos de conhecimento:

a) Conhecimento tácito: é o que está armazenado no cérebro de uma pessoa; é altamente pessoal, difícil de formalizar e comunicar, está fortemente ligado às ações e ao comprometimento do indivíduo em um contexto específico.

b) Conhecimento explícito: é formal e sistemático, é fácil comunicar e compartilhar, está contido em documentos ou outras formas de armazenamento diferente do cérebro humano, como manual de especificação ou sistema de computador.

Para Uriarte (2008), uma definição simples para gestão do 
conhecimento é a conversão do conhecimento tácito em conhecimento explícito e compartilhado dentro da organização, ou seja, a gestão do conhecimento é definida como processo através do qual a organização gera valor a partir de seu conhecimento intelectual e ativo. Bertels (2003, apud URIARTE, 2008, p.13) complementa que a gestão do conhecimento é conceituada como a "gestão para a renovação contínua do conhecimento organizacional".

$\mathrm{Na}$ visão de Nonaka e Takeuchi (2008), o conhecimento tático e explícito são mutuamente complementares e a interação entre eles é chamada de "conversão do conhecimento", que consiste em um processo social entre indivíduos. Assim, através do processo de "conversão do conhecimento", o conhecimento tácito e o conhecimento explícito expandemse em termos de qualidade e quantidade (NONAKA, 2008).

Nonaka (2008) apresenta quatro modos diferentes de conversão do conhecimento, são eles: Socialização: É o processo de compartilhamento de experiências, tais como modelos mentais e habilidades técnicas e a experiência; Externalização: É um processo de articulação do conhecimento tácito em conceitos explícitos. É o processo de criação do conhecimento quando o tácito se torna explícito assumindo a forma de metáforas, analogias, conceitos, hipóteses e modelos; Combinação: É um processo de montagem de novos conhecimentos. É a combinação de partes diferentes do conhecimento explícito existentes em novos conhecimentos; Internalização: É o compartilhamento do novo conhecimento explícito entre as pessoas dentro de uma organização. É internalização do novo conhecimento usado para ampliar, entender, e reformular o conhecimento tácito.

Uriarte (2008, p.14) ainda apresenta a Gestão do Conhecimento sob dois aspectos: para gerir pessoas (identificar e mapear os ativos intelectuais dentro de uma organização); e, também, gerir a informação (gerenciar o conhecimento que está na cabeça das pessoas). Sordi (2003, apud Willerding; Dias; Lapolli, 2014, p.30), considera que as organizações que praticam gestão do conhecimento são, comumente, as que se destacam em seus campos de ação, com postura inovadora e sólida no mercado em que atuam. Algumas aplicações são citadas por diversos autores como:

a) Inteligência Empresarial (Business Intelligence) - é definida como a utilização de dados de ontem e de hoje para tomar decisões melhores amanhã. É o processo de coleta, organização, análise, compartilhamento e monitoramento de informações externas e internas que servem de base para tomada de decisão e para gestão de negócios (SCHAPES, 2008);

b) Gestão do Capital Intelectual - "Capital Intelectual é o domínio de conhecimentos, experiência acumulada, tecnologias da organização, relacionamento com clientes e habilidades profissionais" (EDVINSSON, 
998, apud ARA, 2005, p.48);

c) Gestão de Competências - pode ser definida como uma proposta de gestão a ser aplicada em empresas que optaram por um sistema integrado, no qual a competência é o primordial para o sucesso sustentável da organização (FREITAS, 2005, p.26);

d) Inteligência Competitiva - pode ser definida como processo de melhoria da competitividade no mercado por meio de uma maior compreensão dos concorrentes da empresa e do ambiente competitivo (MALHOTRA, 2012, p.12).

\subsection{GESTÃO DE PESSOAS}

Para Chiavenato (2008, p.08), a gestão de pessoas é uma área sensível e dependente do contexto de cada organização, não se limitando a uma simples definição, pois o seu comportamento é indeterminado e situacional e dependente de vários aspectos como a Cultura Organizacional, a Estrutura Organizacional, as Características do contexto, o Negócio da Organização, a Tecnologia utilizada, os Processos internos e outras variáveis a considerar.

No contexto organizacional atual, onde tudo é considerado como recurso, seja material, financeiro e tecnológico, grandes empresas têm adotado o princípio de que o ser humano é o recurso mais importante, capaz de assegurar o bom uso dos demais recursos com eficiência e eficácia. Para garantir o crescimento e a perpetuidade da empresa, faz-se necessário investir no seu desenvolvimento (CHIAVENATO, 2008, p.04).

\section{DESENVOLVIMENTO}

\subsection{Delineamento da Pesquisa}

Atualmente, observa-se que empresas do setor moveleiro na cidade de São Luís são, em grande parte, filiais ou franquias de grandes empresas já solidificadas no mercado, seja pela qualidade de seus produtos e serviços, seja pela gestão de pessoas e processos. Mas conforme estudo elaborado pelo SEBRAE (2011), houve um faturamento do setor moveleiro nos últimos 10 anos, até 2011 , cujo crescimento foi de $1,38 \%$ e a concentração de empresas do setor nos polos Maranhão, Piauí e Tocantins é de até 100 empresas.

O foco destas microempresas não está no crescimento do negócio ou do reconhecimento da marca, mas em vender seu produto. Em geral, sem qualidade no atendimento e nos serviços prestados, com os prazos nem sempre atendidos e atuando no mercado de forma limitada. Esta limitação se dá pelo perfil da empresa que é pouco especializada e apresenta baixa relação de investimento e mão-de-obra (GONÇALVES; KOPROWKI, 1995, 
apud OLIVEIRA, 2006). Vale ressaltar que uma das características destas microempresas é a de ser propriedade de um indivíduo ou de um pequeno grupo de pessoas (familiar), que possui uma marcenaria própria ou em parceria e onde o proprietário desempenha o papel de gerente e, às vezes, de vendedor.

\subsection{Dados Coletados da Pesquisa}

Perfil do microempreendedor lojista: o proprietário possui grau de escolaridade superior incompleto, ocupa o cargo de administrador e vendedor, com remuneração média mensal de $\mathrm{R} \$ 600,00$ a $\mathrm{R} \$ 1200,00$. O tipo de vínculo empregatício está definido como negócio próprio. Seu conhecimento sobre o setor foi adquirido por tradição familiar e, após fundar a empresa, buscou conhecimento pela internet. Com a realização da entrevista, pode-se constatar que o microempresário não possui conhecimentos de administração, não faz nenhum tipo de planejamento estratégico e não conhece as ferramentas estratégicas que podem ser utilizadas.

Identificação e Perfil da Microempresa: foi inicialmente selecionada uma microempresa do ramo de atividade moveleira que iniciou suas atividades em 2014, cujo capital social investido foi de $R \$ 4.500,000$. A empresa funciona em imóvel próprio, adequado apenas para produção atual. Foi aplicado um questionário elaborado pelo Sebrae (2005) do Distrito Federal, como instrumento para coleta de dados.

A entrevista aconteceu em três momentos, no período de três semanas, tendo os seguintes objetivos: a) Identificação do perfil da empresa e do microempresário; b) Identificação sobre o uso de ferramentas estratégicas; c) Apresentação das práticas da Gestão do Conhecimento para o mercado moveleiro.

Aspectos da Produção e Equipamentos: as principais linhas de produtos da microempresa são: estantes, móveis para escritório, móveis infanto-juvenil, armários embutidos, armários de cozinha e móveis para terraço. Na produção, é utilizada somente madeira de reflorestamento, a maior parte adquirida no próprio estado. Os materiais mais utilizados são a madeira maciça e o MDF, cada um correspondendo a $44 \%$ do material utilizado. Não existe estoque dos materiais.

Quanto às máquinas e equipamentos existentes na microempresa, listam-se: ferramentas básicas (7 unidades), furadeiras (2 unidades, esquadrejadeira ( 1 unidade), serra circular (1 unidade) e plaina moldureira (1 unidade). Foi constatado que o tempo de uso destas está acima de 9 anos.

Aspectos de Controle e Qualidade: Aempresa não possui programa 
de qualidade para controle da sua produção. Suas dificuldades são: falta de informação sobre programa de qualidade existente, falta de recursos financeiros para implantação dos programas, falta de planejamento.

Aspectos da Comercialização dos produtos: a quantidade de vendas para o mercado local é de $100 \%$, sem perspectiva para comercialização para fora do estado e exterior. Não há dificuldades de vendas dos produtos por parte do proprietário. $O$ faturamento está concentrado apenas no mercado local.

Os canais de vendas mais utilizados pela microempresa são: por encomenda (48\%) e vendas diretas ao consumidor (52\%). A microempresa não atua no comércio atacadista e varejista. $O$ faturamento médio foi de $\mathrm{R} \$ 1.700,00$, nos últimos 12 meses. O gráfico 1 apresenta os meses de baixa e alta demanda (de outubro de 2014 a junho de 2015). Sendo que, no segundo semestre de 2014, não houve vendas nos meses de julho, agosto e setembro, justificado pelo início de preparação do local e instalação dos equipamentos.

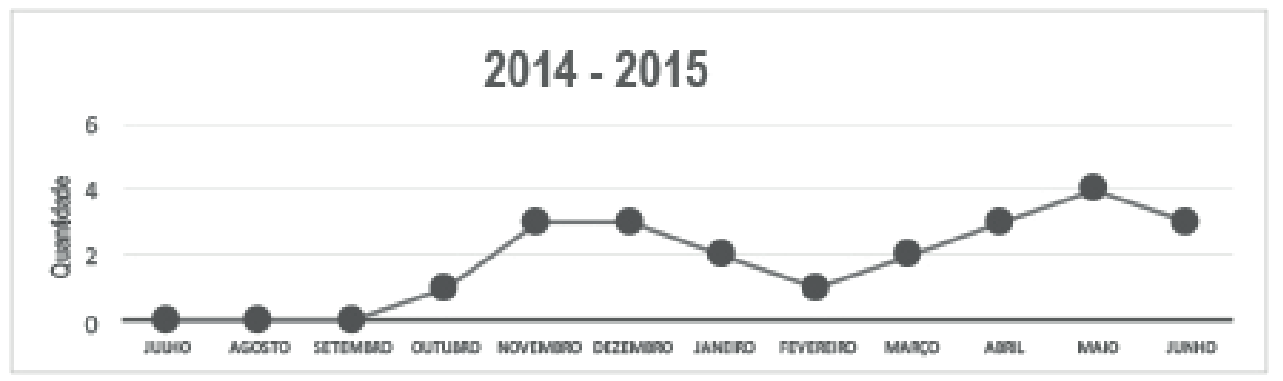

Gráfico 1 - Registro das vendas por mês.

Fonte: Autor

\subsection{Proposta de Modelo de Gestão do Conhecimento}

Para esta proposta de um modelo de gestão de conhecimento para microempresa do setor moveleiro de São Luís, o microempresário deve considerar fatores externos e internos que podem influenciar seu negócio, que serão apresentados a seguir.

\section{1 - Considerando os Fatores Internos}

Refere-se a tudo que deve ser observado no que diz respeito a conhecimento do negócio e o conhecimento que está nas pessoas, seja em atividades de produção ou processos gerenciais no setor moveleiro. No modelo proposto, para se obter uma vantagem competitiva é essencial que o conhecimento tácito se transforme em conhecimento explícito. $O$ modelo propõe que deve ser considerado cada elemento que compõe a estrutura operacional dentro da empresa, que são seus processos, pessoas 
e produtos.

Recomenda-se que o microempresário faça a Gestão do Conhecimento para auxiliar na identificação do conhecimento através da prática da Gestão do Capital Intelectual, que é o processo de identificação, compartilhamento e utilização dos conhecimentos de todos em uma empresa, o qual pode ser criado e capturado em três lugares:

a) Pessoas: deve ser gerado a partir do relacionamento entre funcionários, clientes e fornecedores, identificando os principais consumidores e diferenciando-os entre si, para assim, capturar suas preferências e comportamentos. Deve se selecionar os fornecedores mais capacitados e organizá-los por segmentação. As informações coletadas devem estar em único lugar para que todos tenham acesso, como portal em web sites ou em pastas e arquivos. Quanto aos funcionários sugere-se o mapeado de suas competências, separando os mais experientes daqueles que possuem pouco conhecimento. Recomenda-se que todo o quadro funcionário seja orientado a discutir e focar suas ações no que é fundamental para qualidade no trabalho e crescimento da empresa (CARBONE, 2006, p.71).

b) Processos: recomenda-se a identificação dos processos mais importantes do setor moveleiro, que geram valor para o negócio. Deve-se mapear as sequências de tarefas e atividades-chave, definindo suas metas e determinado os resultados esperados de cada um, assim como suas relações e seus resultados produzidos. O produto final dessa analise deve ser um mapa, demonstrando o fluxo operacional do processo produtivo e operacional, para a modelagem deste processo de negócio, para o qual pode-se utilizar a ferramenta Bizagi Modeler 4 .

c) Produtos: sugere-se que o vendedor conheça bem o produto ou serviço que está vendendo, adquirindo conhecimento a partir das informações daquilo que está oferecendo, com o propósito de transmitir confiança para o cliente ao negociar cada projeto.

\section{2 - Externalização com Gestão de Competências}

No caso da microempresa moveleira observada, todo conhecimento de produção e operacional está tácito. Para se tornar explicito, o modelo propõe a utilização do modo de conversão do conhecimento denominado Externalização. Para isso, o microempresário deve fazer uso do diálogo e da reflexão para capturar de um grupo de funcionários informações sobre modos de operação e montagem de peças, tipos de ferramentas utilizadas e diferentes tipos de matérias-primas. A captura dá-se através da

$4 \quad$ Uma das ferramentas de diagramação de processos em BPMN mais conhecidas do mercado. 
documentação (manual, procedimentos, gráficos, símbolos ou modelagem de processos produtivos) das informações obtidas dos funcionários mais experientes.

O modelo propõe que se deve estimular a interação entre funcionários com o objetivo de criar, armazenar e compartilhar o ativo intelectual capturado, que é o conhecimento gerado da troca de informação e exposição de experiências. Para isso, sugere-se a criação de um ambiente de colaboração e compartilhamento de ideias contínuo. Com a identificação dos conhecimentos de cada funcionário, deve-se mapear suas competências. No caso de funcionários menos experientes, este mapeamento identificaria o que precisa ter ou desenvolver.

Recomenda-se utilizar a Gestão de Competências, que se traduz no processo de identificação dos conhecimentos, habilidades e atitudes que são estratégicas para o negócio, conforme explicado por Siqueira (2005), como: verificar quais competências já estão presentes na empresa; identificar conhecimentos que são estratégicos para o negócio; e desenvolver nos funcionários habilidades e atitudes para atender aos objetivos da empresa.

Deve-se criar um modelo de mapeamento de competências para identificar os pontos fortes e fracos dos funcionários e alinhar as atitudes e as habilidades ao negócio. Neste caso, as competências necessárias a serem desenvolvidas por função para atuar no mercado moveleiro. Maria Ângela Soares Lopes, em Ideias de negócio SEBRAE (2008), sugere que seriam:

a) Administrador deve ter a capacidade para: lidar com imprevistos, reconhecer e definir problemas, atuar preventivamente, ter raciocínio lógico, crítico e analítico, ter conhecimento de gestão empresarial, ter habilidade de relacionamentos, ter habilidade para negociar, ter próatividade, ter inteligência emocional para lidar com possíveis conflitos, possuir disciplina;

b) Projetista deve ter a capacidade de: boa visão espacial, capacidade de comunicação, habilidade manual, raciocínio espacial desenvolvido, sensoestético, concentraçãoe atenção a detalhes, criatividade, para realizar um trabalho de qualidade e atender satisfatoriamente às necessidades do cliente, capacidade para trabalhar em equipe;

c) Vendedor(a) deve ter a capacidade de: boa diç̧ão, conhecimento do ramo, conhecimento técnico dos produtos, cortesia e educação para com os clientes e colegas, capacidade para trabalhar em equipe, capacidade de comunicação, inteligência emocional para lidar com possíveis conflitos;

d) Montador deve ter a capacidade de: primazia pelo acabamento, pró-atividade, capacidade de resolver problemas, cortesia e 
educação para com os clientes e colegas, capacidade de comunicação e habilidade para interpretar manuais;

e) Ajudante do Montador deve ter a capacidade de: trabalhar em equipe, cortesia e educação para com os clientes e colegas e habilidade para interpretar manuais.

\section{3 - Internalização com Gestão de Competências}

O microempreendedor deve articular todo o conhecimento explícito em tácito por meio de programas de treinamentos, realizando reuniões periódicas para compartilhar ideias e experiências, promovendo a disseminação de todo conhecimento gerado dessa interação entre pessoas. Inclui também capacitar os integrantes nos processos de organização do trabalho e execução, como: identificar recursos necessários; estimar tempo de montagem e produção; elaborar ficha técnica do produto; fazer roteiro de fabricação e desenhos; preparação de máquinas e equipamentos; operações de corte e operações de furação; operações de lixamento e operações de montagem de partes.

O modelo propõe que, por meio do modo de conversão Internalização, o conhecimento deixa de ser pessoal para se tonar conhecimento organizacional. Sendo assim, o microempresário deve valorizar as pessoas e seus conhecimentos, motivando-os a trabalhar com o foco no negócio, pois isto é importante para o crescimento da empresa.

\section{Considerando os Fatores Externos}

No modelo proposto, considera-se que o microempresário deve formar uma equipe alinhada aos objetivos da microempresa, por isso, o modelo propõe a observação dos fatores externos, que são: ações dos concorrentes e tendência de mercado. Recomenda-se que, mesmo com uma equipe pequena, as pessoas sejam direcionadas de forma a aumentar os lucros e atrair novos clientes, analisando o que há de novo mercado em tecnologias aplicadas a produção de móveis, novos materiais e a linha de produto com maior aceitação no mercado.

\section{Inteligência Competitiva}

A Inteligência Competitiva, na Gestão de Conhecimento, serve para planejar, coletar e analisar a informação, visando apoiar a tomada de decisão, de modo sistemático e contínuo. $O$ uso do modelo contribui para assegurar a competitividade por meio do monitoramento das ações dos concorrentes e das tendências do mercado. Recomenda-se que este papel deve ser desempenhado pelo dono/gerente do negócio, realizando um Benchmarking para capturar as boas práticas, como programa de marketing, sistema de logística, processo de montagem, programa de garantia, atendimento pós-venda, limpeza, manutenção programada e 
programa de qualidade.

\section{Inteligência Empresarial}

Recomenda-se manter um processo de aprendizagem coletiva e um ambiente de pesquisa constante sobre boas práticas, especificação de materiais e equipamentos e um entendimento claro dos processos. Isso inclui conhecer ações da concorrência como: identificar as melhores estratégias, conhecer o comportamento do setor e encontrar novas oportunidades e na melhoria das ações internas. Recomenda-se que o microempreendedor busque conhecimentos de administração de empresas e conheça as principais ferramentas e técnicas para planejamento estratégico A figura 1 apresenta a aplicação da Gestão do Conhecimento na observação de fatores internos e externos, utilizado para gerar o modelo aqui proposto:

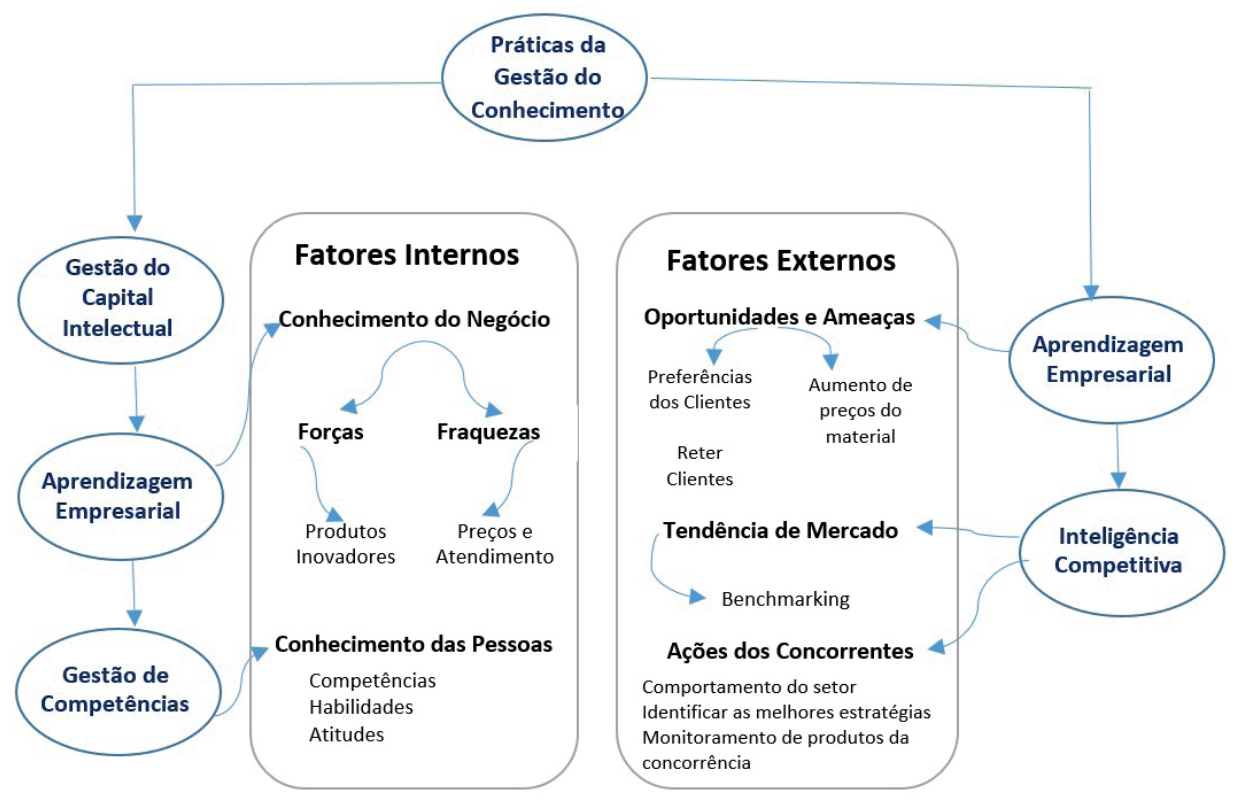

Figura 1 - Práticas da gestão do conhecimento para o contexto moveleiro. Fonte: Autor

\section{CONCLUSÃO}

Com a realização desta pesquisa, observou-se que, sob a ótica do microempreendedor moveleiro, certos tipos de conhecimento como entendimento bem claro de processos de produção, domínio das especificações de produtos e materiais e gestão de competências, podem influenciar no crescimento da microempresa. 
Dessa forma, considera-se que é possível aplicar a Gestão do Conhecimento em microempresas e que isto traz efeitos positivos, quando há um efetivo de funcionários bem reduzido. Pode-se perceber, também, que houve da parte do microempreendedor e de seus poucos funcionários o interesse por adoção de práticas simples como: a busca continua por qualificação profissional, planejamento de atividades, o registro de vendas e o cadastro de clientes.

Entende-se que, independente do porte da empresa, que estabelecer a missão, a visão e os valores para uma microempresa, é tão importante quanto para uma grande empresa e que, em vista dos argumentos apresentados, é-se levado a acreditar que a sua disseminação deve ser o início a ser considerado para que uma microempresa se torne competitiva e busque o diferencial para os seus produtos, investindo nas pessoas e em seu capital intelectual.

Conclui-se que, com a realização desta pesquisa, foi possível:

a) Medir o conhecimento das pessoas do setor moveleiro relacionado a processos e negócio;

b) Modelar um processo de atendimento ao cliente para microempresas deste setor;

c) Sensibilizar os microempresários envolvidos na pesquisa sobre a importância da adoção da Gestão de Conhecimento;

d) Elaborar um modelo de Gestão de Pessoas com práticas simples, utilizando a Gestão do Conhecimento, com base nas orientações da cartilha de Gestão do Conhecimento na Pequena Empresa, elaborado pelo SEBRAE (2010) de Brasília/DF.

Deste modo, é possível adotar a Gestão de Conhecimento em microempresas ao adotar práticas simples e que requerem um baixo investimento do microempresário, ao mesmo tempo em que isto permite melhorar seus processos e aumentar a qualidade dos serviços ofertados. Além de, caso haja um plano de expansão da microempresa, tais níveis de mapeamento e formalização de procedimento dos processos e serviços irão auxiliar os microempresários de forma mais segura.

\section{REFERÊNCIAS}

ABDUCH SANTOS, J. A. Licitações e o Estatuto da Microempresa e Empresa de Pequeno Porte. Curitiba: Juruá, 2009.

AGÊNCIA SEBRAE. Setor moveleiro maranhense está em franca 
expansão. Disponível em:<http://imirante.globo.com/maranhao/noticias/2003/08/06/ setor-moveleiro-maranhense-esta-em-franca-expansao.shtml>. Acesso em: 13 maio 2015.

BUKOWITZ, W. R.; WILLIAMS, R. L. Manual de Gestão do Conhecimento. Porto Alegre: Bookman, 2002.

CARBONE, PedroPaulo. GestãoporCompetências-Umanovametodologia de gerenciamento do capital humano. Disponível em: <http://www.mundopm.com.br/ download/gestao.pdf>. Acesso em: 13 maio 2015.

CHIAVENATO, I. Gestão de Pessoas: 0 novo papel dos recursos humanos nas organizações. - 3.ed, Rio de Janeiro: Elsevier, 2008.

DAVENPORT, T. H.; DAVID, W.; BEERS, M. C. Successful knowledge management projects. Sloan management review, v. 39, n. 2, p. 43-57, 1998.

DAVENTPORT, T. H.; LAURENCE, P. Conhecimento Empresarial: como as organizações gerenciam o seu capital intelectual. Rio de Janeiro: Elsevier, 2003. $14^{\mathrm{a}}$ edição.

FILEMON, A.; URIARTE, J. Introduction to Knowledge Management. ASEAN Foundation, Jakarta, Indonésia, 2008.

FREITAS, A. Gestão de Competências: Uma proposta para garantir que sua empresa seja cada vez mais competente. Clube de Autores, 2005.

LARA, C. R. D. A atual gestão do conhecimento: a importância de avaliar e identificar o capital humano nas organizações. São Paulo: Nobel, 2005.

MALHOTRA, N. K. Pesquisa de Marketing: uma orientação aplicada. Porto Alegre-RS: Bookman, 2012.

MENDES, Alexandre. Gestão do Conhecimento - A espiral do conhecimento. Disponível em: <http://imasters.com.br/artigo/10659/gerencia-de-t/ gestao-do-conhecimento-a-espiral-do-conhecimento>. Acesso em: 13 maio 2015.

NÓBREGA BARBOSA, M.F. (2006) Gestão das microempresas do comércio de Sousa - Paraíba. Edição electrónica. Texto completo em: www.eumed. net/libros/2006b/mfnb2/

OLIVEIRA, J. O. Pequena empresa no Brasil: Um estudo de suas características e perspectivas. Disponível em: <http://www.usjt.br/prppg/revista/ integracao/integracao_44.php> Acesso: 20 abril 2015.

Portal Gestão. O que é o capital intelectual? Disponível em: <https://uww. 
portal-gestao.com/item/6347-o-que-\%C3\%A9-o-capital-intelectual.html>. Acesso em: 13 maio 2015.

PARADIGMA INTERNET. Gestão do Conhecimento na prática. Disponível em: $\quad<$ http://www.paradigma.com.br/gestao-do-conhecimento-na-pratica/artigos/ gestao-do-conhecimento-na-pratica>. Acesso em: 13 maio 2015.

REIS, C. Aprendizagem Organizacional e Gestão do Conhecimento. Disponível em: http://institutopharos.com.br/aprendizagem-organizacional-e-gestaodo-conhecimento/. Acesso em: 28 maio 2015.

SANTOS,A. L.; KREIN, J.D.; CALIXTRE,A. B. Micro e pequenas empresas: mercado de trabalho e implicação para o desenvolvimento. Rio de Janeiro: IPEA, 2012.

SIQUEIRA, M. C. Gestão Estratégica da Informação. Rio de Janeiro: Brasport, 2005.

TAKEUCHI, H.; NONAKA, I. Gestão do conhecimento. Porto alegre RS: Bookman, 2008.

SEBRAE. A Gestão do Conhecimento na Pequena Empresa. Disponível

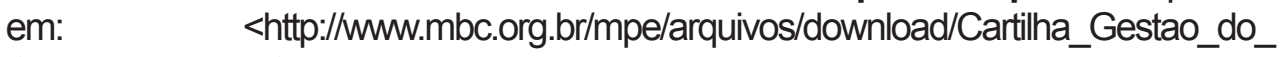
Conhecimento.pdf>. Acesso em: 13 janeiro 2015.

SEBRAE. Como montar uma loja de móveis planejados. Disponível em:<http://www.sebrae.com.br/sites/PortalSebrae/ideias/Como-montar-uma-loja-dem\%C3\%B3veis-planejados>. Acesso em: 13maio 2015. 